\title{
A retrospective study on surgical management of ovarian tumours in a teritary care semiurban hospital
}

\section{S. Divya Ranjitha*, Kavitha Karthikeyan, Amrita Priscilla Nalini}

Department of Obstetrics and Gynecology, Chettinad Health and Research Institute, Kelambakkam, Chennai, Tamil Nadu, India

Received: 20 July 2017

Revised: 02 September 2017

Accepted: 05 September 2017

\section{*Correspondence:}

Dr. S. Divya Ranjitha,

E-mail: divyaranjitha2390@gmail.com

Copyright: (c) the author(s), publisher and licensee Medip Academy. This is an open-access article distributed under the terms of the Creative Commons Attribution Non-Commercial License, which permits unrestricted non-commercial use, distribution, and reproduction in any medium, provided the original work is properly cited.

\section{ABSTRACT}

Background: The prevalance of ovarian tumors is around 1-3\%. The accurate diagnosis and appropriate management of ovarian tumors is a real challenge to gynaecologists. The aim of the study was to analyse the risk factors, clinical presentation, surgical procedure and histopathological report in patients with surgically managed ovarian tumours.

Methods: We conducted a retrospective study by collecting the data of patients operated in the department of Obstetrics and Gynecology at Chettinad Hospital and Research Institute, Kelambakkam. A total of 118 case records were studied.

Results: $20.3 \%$ were nulliparous. $79.7 \%$ were multiparous. $10.2 \%$ were $<20$ years, $47.2 \%$ were $20-40$ years, $39.2 \%$ were $40-60$ years, $3.4 \%$ were $>60$ years. $72.9 \%$ were premenopausal. $27.1 \%$ were postmenopausal. $25.4 \%$ presented with acute abdominal pain, $11.9 \%$ with mass abdomen, $30.5 \%$ with chronic pain abdomen and $32.2 \%$ were incidentally diagnosed. $20.4 \%$ underwent ovarian cystectomy, $18.6 \%$ ovariotomy, $30.5 \%$ salpingoophorectomy and $30.5 \%$ total abdominal hystrectomy with bilateral salpingoophorectomy. Most common histopathology report was simple cyst in $44 . \% .31 .3 \%$ had serous cystadenoma, $9.3 \%$ had mucinous cystadenoma, $9.3 \%$ had teratoma, $2.5 \%$ had brenner tumour, $1.7 \%$ borderline tumours and $1.7 \%$ malignancy (Serous cystadenocarcinoma).

Conclusions: Elective surgical management of ovarian tumours is better option for reducing emergency laparotomies for torsion and rupture and also for obtaining a conclusive histopathological diagnosis in suspicious cases. The choice between laparoscopy and laparotomy should made after making appropriate preoperative evaluation.

Keywords: Frozen section, Laparoscopic surgeries, Ovarian tumours

\section{INTRODUCTION}

The prevalence of ovarian tumours among gynaecological inpatient admissions is around $1-3 \% .75 \%$ of these tumours are benign. Most of the tumours in reproductive age group are benign. ${ }^{1}$ There are a varied clinical presentation of benign ovarian tumours. The diagnosis and appropriate management is a challenge to gynaecologists. Most cases of ovarian tumours are incidentally diagnosed in ultrasound. Bi manual pelvic examination coupled with transvaginal sonography forms the main screening method for ovarian tumours. ${ }^{2}$ Chances of malignancy is more common in the adolescent and post-menopausal age groups. The incidence of malignant ovarian tumours in a patient younger than 45 years is 6$6.5 \%$. It is difficult to clinically differentiate malignant tumours in few patients. The addition of CA125 levels estimation and ultrasound will further aid in the appropriate diagnosis. Reports say around $0.4 \%$ of the tumours diagnosed preoperatively as benign are proven to be malignant post operatively. ${ }^{3}$ Management of ovarian tumours is quite complex ranging from expectant follow 
up to radical surgeries depending on the clinical scenarios. Ovarian tumours are ultimately very much challenging also to the pathologists. This is because ovaries have totipotential cell rests and can give rise to a wide range of tumours than any other organ in the body. ${ }^{4}$ This is a retrospective observational study done to review patients with ovarian tumours who underwent surgical management.

\section{METHODS}

This is a retrospective observational study of patients with ovarian tumours who were surgically managed during a 3-year period from January 2014 to December 2016, carried out in the department of Obstetrics and Gynaecology, Chettinad hospital and research institute, Kelambakkam.

Data relating to age, parity, clinical presentation, clinical diagnosis, ultrasound findings, tumour markers, surgical procedure, surgical findings were collected from the registers and case records from the medical records department. Histopathology reports were obtained from the pathology department. The inclusion criteria were all cases of ovarian tumors subjected to surgery. A total of 118 cases were obtained and analysed. About 7 other cases which were suspected to be ovarian tumors and underwent surgery were para ovarian cysts and hydrosalpinx and were excluded from the study. The obtained data was tabulated and analysed.

\section{RESULTS}

The total number of patients studied with surgically managed ovarian tumours were 118. Patients in age group less than 20 years were $12(10.2 \%), 20-40$ years were 56 $(47.4 \%), 40-60$ years were $46(38.9 \%)$ and $>60$ years were $4(3.4 \%)$.

Table 1: Age.

\begin{tabular}{|l|l|}
\hline Age & No of patients $(\%)$ \\
\hline$<20$ years & $12(10.2 \%)$ \\
\hline $20-40$ years & $56(47.4 \%)$ \\
\hline $40-60$ years & $46(38.9 \%)$ \\
\hline$>60$ years & $4(3.4 \%)$ \\
\hline
\end{tabular}

Table 2: Parity.

\begin{tabular}{|ll|}
\hline Parity & No of patients (\%) \\
\hline Nulliparous & $24(20.3 \%)$ \\
\hline Multiparous & $94(79.7 \%)$ \\
\hline
\end{tabular}

Table 3: Clinical features.

\begin{tabular}{|ll|}
\hline Clinical feature & No of patients $(\%)$ \\
\hline Asymptomatic & $30(25.4 \%)$ \\
\hline Acute abdominal pain & $14(11.9 \%)$ \\
\hline Chronic abdominal pain & $36(30.5 \%)$ \\
\hline Abdominal mass & $38(32.2 \%)$ \\
\hline
\end{tabular}

24 patients were nulliparous $(20.3 \%) .94$ patients were multiparous $(79.7 \%)$. There were no prepubertal patients. 86 Patients $(72.9 \%)$ were premenopausal. 20 patients $(60.9 \%)$ were post- menopausal. $12(10.2 \%)$ patients underwent hysterectomy. 4 patients (3.4\%) were antenatal with ovarian tumour complicating pregnancy.

30 patients $(25.4 \%)$ presented as emergency to the causality with acute abdominal pain. 14 Patients (11.9\%) presented with history of abdominal mass. 36 patients $(30.5 \%)$ presented with chronic abdominal pain. In 38 patients $(32.2 \%)$ it was an incidental diagnosis and they were asymptomatic. While testing for tumour markers, CA 125 was elevated in $8(6.8 \%)$ patients.

Table 4: Size of tumour.

\begin{tabular}{|ll|}
\hline Size & No of patients $(\%)$ \\
\hline$<5 \mathrm{~cm}$ & $5(4.2 \%)$ \\
\hline $5-8 \mathrm{~cm}$ & $54(45.7 \%)$ \\
\hline $9-15 \mathrm{~cm}$ & $42(35.5 \%)$ \\
\hline$>15 \mathrm{~cm}$ & $17(14.4 \%)$ \\
\hline
\end{tabular}

Table 5: Type of procedure.

\begin{tabular}{|ll|}
\hline Surgery & No of patients $(\%)$ \\
\hline Laproscopy & $16(13.5 \%)$ \\
\hline Laparotomy & $102(86.4 \%)$ \\
\hline
\end{tabular}

A clinical diagnosis of benign tumours was done in 105 patients $(88.9 \%)$ and of malignant tumours is 13 $(11.01 \%)$ patients. Size of the tumour was $<5 \mathrm{~cm}$ in 5 patients $(4.2 \%), 5-7 \mathrm{~cm}$ in 54 patients $(45.7 \%), 8-15 \mathrm{~cm}$ in 42 patients $(35.5 \%)$ and $>15 \mathrm{~cm}$ in 17 patients $(14.6 \%)$. 16 patients $(13.6 \%)$ underwent laparoscopic surgery and $102(86.4 \%)$ patients underwent laparotomy.

Ovarian cystectomy was done in 24 patients $(20.4 \%)$, oophorectomy in 22 patients (18.6\%), Salpingoophorectomy in 36 patients $(30.5 \%), 36$ patients $(30.5 \%)$ underwent total abdominal hysterectomy with bilateral salpingoophorectomy and $5(4.2 \%)$ patients had additional infracolic omentectomy and pelvic and para aortic lymph node dissection.

Analyzing the histopathology reports 37 patients $(31.3 \%)$ had serous cystadenoma, 11 patients $(9.3 \%)$ had mucinous cystadenoma, 11 patients $(9.3 \%)$ had mature teratoma, $3(2.5 \%)$ patients had brenner tumour, $2(1.7 \%)$ had borderline mucinous cystadenoma, 2 (1.7\%) had serous cystadenocarcinoma. $52(44.2 \%)$ patients had simple ovarian cysts and in the histopathological reports.

Table 6: Procedure done.

\begin{tabular}{|ll|}
\hline Procedure Done & No of patients (\%) \\
\hline Ovarian cystectomy & $24(20.3 \%)$ \\
\hline Ovariotomy & $22(18.6 \%)$ \\
\hline Salpingoovariotomy & $36(30.5 \%)$ \\
\hline TAH with BSO & $36(30.5 \%)$ \\
\hline
\end{tabular}


Table 7: Histopathological reports.

\begin{tabular}{|ll|}
\hline HIPE & No of patients $(\%)$ \\
\hline Serous cystadenoma & $37(31.3 \%)$ \\
\hline Mucinous cystadenoma & $11(9.3 \%)$ \\
\hline Mature teratoma & $11(9.3 \%)$ \\
\hline Brenner tumour & $3(2.5 \%)$ \\
\hline Borderline cystadenoma & $2(1.7 \%)$ \\
\hline Serous cystadenocarcinoma & $2(1.7 \%)$ \\
\hline $\begin{array}{l}\text { Simple ovarian and paratubal } \\
\text { cysts }\end{array}$ & $52(44.1 \%)$ \\
\hline
\end{tabular}

\section{DISCUSSION}

Mean age group of patients with ovarian tumours who required surgery is between $20-40$ years. $88.9 \%$ of tumours were benign. Benign tumours are more common in the reproductive age group. Nulliparity doubles the risks of ovarian cancer. ${ }^{5}$ In our study only $20.3 \%$ patients are nulliparous. Treatment for infertility with ovulation induction drugs further increases the risks of malignancy. This is similar to the study by Srinivas K, Harish Babu BG, KV Malini retrospective study of clinical and pathological features of benign ovarian tumours. ${ }^{6}$ The incidence of postmenopausal patients was $16.9 \%$ which again showed that most patients in the reproductive age group have benign ovarian neoplasm. Among postmenopausal patient's majority of tumours were still found to be benign.

Around $25.4 \%$ patients presented as emergency with acute abdominal pain to the casuality. Out of which 93.3\% had torsion ovarian cysts as the diagnosis and $7.7 \%$ patients had ruptured ovarian cysts as the diagnosis. Patients presenting as emergency were taken up for immediate laparotomy. All patients underwent either oophorectomy or salpingoophorectomy. Conservation of ovarian tissue was not possible in all the cases. This could have been avoided if the procedures were planned electively in such patients, provided an earlier diagnosis was made. Laparoscopic surgery was not also easily available to tackle emergency situations due to lack of experts. Future fertility becomes questionable in such situations especially in young unmarried females. In our study $18(15.2 \%)$ patients were unmarried.

In perimenopausal patients, performing more radical procedures like total abdominal hysterectomy with bilateral salpingoophorectomy is also not possible in emergency situations due to lack of adequate preoperative preparation. Prior studies recommended expectant management for simple ovarian cysts $<8 \mathrm{~cm}$ in reproductive age group. ${ }^{7}$ Among patients who presented as emergency, $63.3 \%$ had size of the cyst $<8 \mathrm{~cm}$, indicating the need for some means of elective intervention in these group of patients. It could be any mode of treatment from ultrasound guided aspiration to laparoscopic ovarian cystectomy. $13.5 \%$ patients underwent laparoscopy. It is better to preoperatively differentiate benign from malignant neoplasm. As the rate of cyst rupture during surgery was higher in laparoscopy compared to laparotomy as showed by Shrota et al. ${ }^{7}$ Most tumours were of the size between $5-15 \mathrm{~cm}$. There was a risk of intra operative rupture for cysts $>10 \mathrm{~cm}$. Increased risk of malignancy is also reported in patients with $>10 \mathrm{~cm}$ tumours. ${ }^{8}$

In our study, frozen section was done for 43 patients $(36.4 \%)$. It is always better to operate ovarian tumours especially with suspicious of malignancy in a setup where the option of frozen section is available. This will avoid both unnecessary radical procedures in those unindicated patients and also the need for secondary extensive lymphnode dissection in patients whose histopathological report turns out to be malignant. According to Gol $\mathrm{M}$ et al histological examination of frozen section biopsies was concordant with final histopathological report in $92 \%$ cases. ${ }^{9}$ Frozen section examination of mucinous tumours showed higher under diagnosis rates in 20\%. The availabilty of oncosurgeon while operating cases of suspected malignancy has to be emphasized. This can be planned by proper preoperative evaluation of the patient with CT, MRI and tumour marker levels. 2(1.7\%) patients had borderline ovarian tumors. Patients with tumours of low malignant potential had excellent prognosis as shown by Demeter A1 et al. ${ }^{10}$

Analysing the histopathological report most patients had simple cyst (44\%). Most of them presented as emergency with torsion. Most common benign ovarian neoplasm was serous cystadenoma in our study also similar to the general occurence. Bilateral tumours were seen in 9 $(7.6 \%)$ patients. Coexistent fibroids and or adenomyosis was seen in 6 patients $(5.08 \%)$. There is no significance of this association with ovarian tumours. 2 (1.69\%) patients presented with ovarian cyst in antenatal period. 1patient presented as acute emergency with torsion. The other case at presented at 14 weeks with incidental diagnosis in ultrasound. Both underwent laparotomy. This was much higher than the incidence shown by Sunander $\mathrm{N}$ et al. ${ }^{12}$ The histopathological diagnosis in both patients in our study was serous cystadenoma.

There is no accepted medical treatment for ovarian cysts. Treatment of functional ovarian masses is expectant. Randomized control trials have not shown any role for oral contraceptive pills in resolution of functional ovarian cysts compared with observation alone. ${ }^{12}$ Oral contraceptive pills are effective in reducing risk of subsequent ovarian cysts and can be offered for women preferring contraception. Surgical management is a better option in most perimenopausal patients with ovarian tumours as the risk of malignancy is completely disproven after obtaining a histopathology report that shows the benign nature of the tumour. It is also the option in patients who will lack follow up, thus allevating the need for emergency laparotomies. It is advisable to plan for elective surgeries with the availability of expertise through laparoscopic approach. The limitations of the surgery are due to complications of anaesthesia, 
postoperative morbidity and wound infection in rare cases.

\section{CONCLUSION}

A significant number of surgeries for ovarian tumours are done as emergency. This would be avoided by reducing the incidence of expectant management options, for smaller ovarian cysts $<8 \mathrm{~cm}$. Laparoscopic surgeries are preferable to laparotomies. More conservative procedures like cystectomies and cyst aspiration with idea of conserving future fertility should always be tried in young females. Tumours suspicious of malignancy should be operated in set up where frozen section and oncosurgeons are available to avoid second look surgeries. Hence it is important to preoperatively differentiate between benign and malignant tumours to plan the best possible surgery for the patient.

Funding: No funding sources Conflict of interest: None declared

Ethical approval: Not required

\section{REFERENCES}

1. Berek JS, Berek and Novak's Gynaecology $15^{\text {th }}$ edition, Lippincott Williams and Wilkins; 2011.

2. Rock JA, Jones HW, Te Linde's Operative Gynaecology, 10th edition, Lippincott Williams and Wilkins; 2011.

3. Kotani Y, Umemoto M, Tobiume T, Shiota M. Ovarian tumour cases that were preoperatively diagnosed as benign but postoperatively confirmed as borderline or malignant after laproscopic surgery.Gynecology and minimally Invasive Therapy. 2013;2:122-5.

4. Kumar P, Malhotra N. Jeffcoate's Principles of Gynaecology, Jaypee Brothers Medical Publishers (P) Ltd., $7^{\text {th }}$ ed;2008.
5. Purdie DM, Bain CJ, Siskind V, Webb PM, Green AC. Ovulation and risk of epithelial ovarian cancer. Int J Cancer; 2003;104(2):228-32.

6. Srinivas K, Harish Babu BG, Malini KV. Retrospective study of clinical and pathological features of Benign Ovarian Tumours. Sch J App Med Sci. 2015;3:1046-50.

7. Shiota M, Mitsuhashi N. National investigation on the rates of open surgery and laparoscopic surgery. Gynecologic and Obstetric surgery. 2010;21:127-31.

8. Rulin MC, Preston AL. Adnexal masses in postmenopausal women. Obstet Gynecol. 1987;70:578-81.

9. Gol M, Baloglu A, Yigit S, Dogan M, Aydin C, Yensel U. Accuracy of frozen section diagnosis in ovarian tumors: is there a change in the course of time?. Internat $\mathrm{J}$ Gynecologic Cancer. 2003;13(5):593-7.

10. Demeter A, Csapo Z, Szantho A, Balega J, Sipos N, Papp Z. A retrospective study of 27 ovarian tumors of low malignant potential. European J Gynaecol Oncol. 2001;23(5):415-8.

11. Sunanda N, Akhila MV, Ovarian tumours associated with pregnancy: a five yera retrospective study in a teritiary care hospital. Int J Reprod Contracept Obstet Gynecol. 2015;4(6):1965-9.

12. Cochrane Update. Oral contraceptives for functional ovarian cysts. Obstet Gynecol. 2009;114:679-80.

Cite this article as: Ranjitha SD, Karthikeyan K, Nalini AP. A retrospective study on surgical management of ovarian tumours in a teritary care semiurban hospital. Int J Reprod Contracept Obstet Gynecol 2017;6:4429-32. 